\title{
User perception towards rewards and learning through digital traditional games
}

\author{
Nur Azzah Abu Bakar* and Noraziah ChePa \\ Senior Lecturer, School of Computing, College of Arts and Sciences, Universiti Utara Malaysia, 06010 UUM \\ SINTOK, Malaysia
}

Received: 1-October-2018; Revised: 20-December-2018; Accepted: 30-January-2019

(C2019 Nur Azzah Abu Bakar and Noraziah ChePa. This is an open access article distributed under the Creative Commons Attribution (CC BY) License, which permits unrestricted use, distribution, and reproduction in any medium, provided the original work is properly cited.

\begin{abstract} learning.

\section{Keywords}

Digital traditional games, Digital congkak, Digital snake and ladder, Game rewards.
\end{abstract}

Younger generation nowadays have been too much exposed and being hooked to digital games such as Slither.io, Clash Royale, Dota 2, Battleplans and 1010 which have made the top five in the list of the most popular and addictive digital games. These digital contemporary games focus on entertainment, fun and excitement. The development of digital traditional games, however, focuses more on preserving culture through a platform suitable to the millennials or the socalled "net generation". Little do they know about traditional games such as congkak, gasing or dam haji which are the symbols for cultural characteristics of their community. A traditional game such as the snake and ladder were also used as a teaching tool for teaching counting. Despite being in digital form since the past few years, these games only met with minimum success when measured in terms of the download rate which is far below the rate of digital contemporary games. In light of this, two prototypes of traditional game have been developed in which the emphasis is given on incorporating rewards to make the games more attractive to the millennials. Data on user perception was gathered through a survey in which seventy respondents tested the prototypes and answered the questionnaire. The result shows that the majority of the respondents agree rewards are important at every level of the games to motivate and engage the players, as well as to help them survive. The result also reveals the positive influence of digital traditional game on

\section{Introduction}

Traditional games are the important part of a culture that can tell others the unique history, lifestyle, values and beliefs of specific communities. Besides exposing children to invaluable life lessons, they carry immense benefits for healthy development of children. Khalid [1] highlighted the benefits such as sharpened gross and fine motor skills, improved control and balance, enhanced hand-eye coordination, increased spatial awareness and greater social skills. Different ethnics throughout the world play the game of their own tradition, some of which might be the same game with slight variations in how it is played or what instruments are used. Malaysia as a multiracial country has plenty of traditional games to promote the different culture of its citizens. Games such as congkak, gasing, ketinting, batu seremban are among the most popular games played by the Malay ethnic.

*Author for correspondence

268
The above-mentioned games, however, have not received much attention from digital industry players. Attempt to preserve or re-create these games is still at infancy level [2]. The fast-growing game technology and digital entertainment industry seem to focus more on digital contemporary games (DCG). Google Play Store now has more than one million apps with roughly 1,250 new apps being added every day. These include digital game apps; as of $3^{\text {rd }}$ September 2018 hundreds of thousands of game publishers have registered on Google Play Store and iOS Apps Store. One survey [3] reveals that players in the United States spent 8.2 billion dollars on digital games in July 2018 and this is the increase of $3 \%$ of the amount spent for the same month in 2017.

In contrast to the exciting figures related to DCG, the progress of digital traditional games (DTG), however, is far left behind. There is a significant difference in the download rate of these apps if compared to DCG. As DCG advances, and little 
efforts being put to bring DTG up to the standard of their counterparts, there is a fear that one day traditional games will vanish. Millennials nowadays are too much exposed and hooked to DCG. Little do they know or care about their own traditional games like congkak, gasing, snake and ladder and many others. Their distinctive characteristics have execrated the situation; even the graduate medical students are finding more engaged in technologysupported interactive learning than in traditional learning [4]. Fortunately, they are naturally very much attracted to digital devices and technologies. Hence, it seems promising to continue overcoming the limitations of the existing DTG.

The rest of this paper is divided into three main sections, i.e. the related work, methodology and findings.

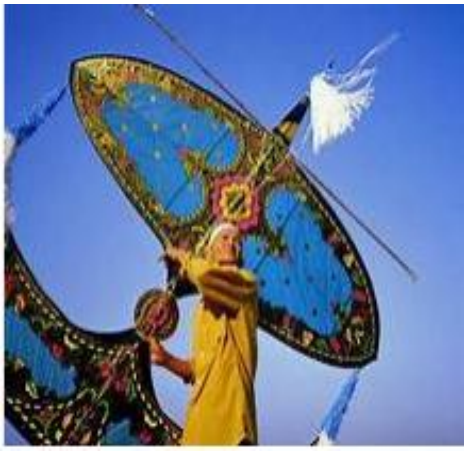

(a) Wau

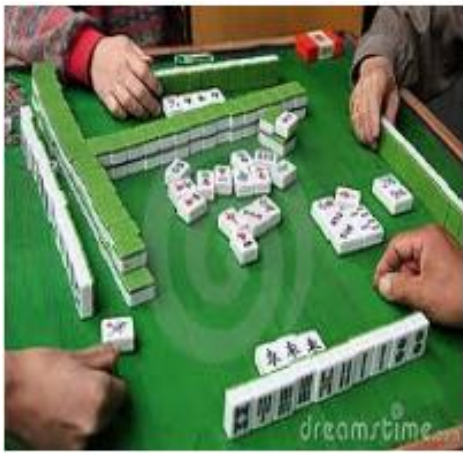

(c) Mahjong

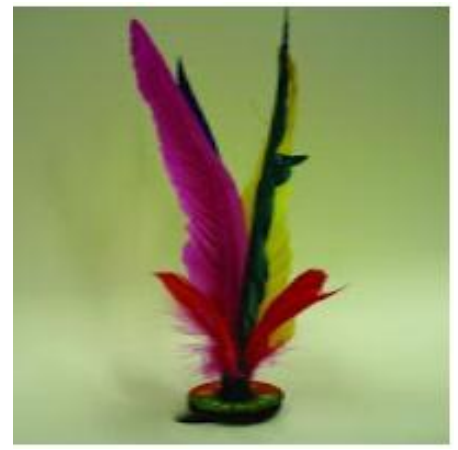

(b) Capteh



(d) Pachisi

Figure 1 Traditional games of Malay, Chinese and Indian

\section{Related work}

Game digitization is a process of converting or creating game content into computer readable format. Some of this are an adaptation of the traditional games with the rules, presentation of the players and environment are managed through electronic means. The field of digital game studies has established its own journals and research organizations. Digital games are said to have influenced physical and mental health, as well as the general well-being of gamers in both positive and negative ways. It is evidenced in [5] that people spent an average of 20 hours a week browsing the Internet; 48 percent of these hours were to play digital or online games. By the age of 21 , a person would typically have spent
10,000 hours on video games [6]. One can think of the negative sides of digital games when they are played beyond a reasonable length of time, such as loss of feeling, of togetherness and poor socialization which results in poor communication and difficulties in one's learning and behavior [7]. However, Felicia [8] by referring to the success of the Nintendo Wii Fit and Nintendo DS highlighted that later studies have shown the positive values of these games if good gaming habits are followed, e.g. play within the appropriate time and environment and moderation of online games.

Past studies [7-10] have proved games, in digital or non-digital format is beneficial for learning as they 
are capable of motivating, engaging and immersing learners. Digital games, especially contain a rich variety of auditory, visual, tactile and intellectual stimuli that make them enjoyable up to the extent that they can be very addictive [8]. According to [11] games used in a learning environment can be categorized as a puzzle (e.g. Sudoku), one-player game (e.g. Solitaire, Tetris), two-player game (e.g. Checkers, Othello) and game for groups (e.g. Monopoly, Star Trek's Holodeck). The use of Wau and Tarik Upih has made Science more interesting and fun to learn. It also enhanced the scientific skills, knowledge and understanding of a scientific concept among students. Furthermore, it developed and nurtured kinesthetic intelligence among the students, which is important to help them develop their own learning processes.

Digitizing traditional games is not meant for learning per se. Instead, it represents one's attempt to preserve his or her own cultural tradition which, with the passing of time are being forgotten and are not passed on to younger generations. Several Malaysian DTGs are now available from Google Play Store such as congkak, dam Kapit, Gasing-X and dam Haji. These apps, however, are just a mere conversion of traditional games into DTG and thus have several limitations that have led to lower user acceptance. Prensky [6] listed twelve characteristics that can make computer games engaging. The games should be fun, a form of play, have rules and goals, interactive, adaptive, have outcomes as well as feedback, have won states, gives a player adrenaline challenge, have a problem, allow social interaction between players as well as giving them emotion while playing. The study conducted by [12] focused on the design issues and suggested seven design characteristics for CCC to be a commercial product.

One aspect that received less attention in the design of DTG is rewarded. Giving rewards in games is desirable, for numerous reasons such as reinforcing player behavior, increasing players' feelings of mastery, scaling difficulty over the course of gameplay, and scaffolding mechanics and player abilities [13]. Experience with DCG also provides insights into the importance of rewards in games. Felicia [8] emphasized on rewarding elements in games when it comes to designing and developing educational games for the so-called "net generation" as they always see rewards as attractive, not just in game playing but also in learning activities. The rewards are good; however, they might be harmful too; therefore, it is important to know what rewards to give and when to or not to give them to gamers
[14]. Effect of rewards on motivation is thoroughly discussed in [15] in response to Deterding's [16] claim that the world is still lacking enough empirical evidence whether it succeeds in promoting user motivation. Other detailed discussion on reward systems can be found in [17-19].

\section{Methodology}

The literature gives insights into the need to add rewards elements in DTG in order to attract the millennials to play the DTG. In response to this, rewards were incorporated into the two prototypes of DTG developed in this study, i.e. congkak and snake and ladder. Four phases were involved as discussed in the following sub-sections.

\section{Phase I: Planning and requirement gathering}

A number of existing congkak and snake and ladder apps were examined in this phase. The aim was to determine whether there is any possibility to redevelop from the existing one, or a need for development from scratch.

Congkak. This app already exists in many versions and one of them was found feasible to be redeveloped. The selected apps were initially a 7 hole Congkak. It worked well when played, but a little bit confusing as it was played in anti-clockwise direction; furthermore, it did not have any rewards incorporated in it. Thus, the redeveloped Congkak must allow players to play in clockwise direction to reflect how the game is actually played with reality. Rewards in a form of points or credits which can be redeemed when needed seemed appropriate for this game.

Snake and Ladder. A new Snake and Ladder is required in which rewards need to be incorporated and different board size need to be designed for different difficulty levels. This app is used to teach Mathematics.

Rewards. The redemption, however, differs between the games depending on the nature the game itself.

\section{Phase 2: Design}

Congkak. The redesign of Congkak focused on three improvements, i.e. (1) add the rewards; (2) improve the gameplay, i.e. from anti-clockwise to clockwise and (3) add more flexibility to the board size which allows players to choose either to play the 6,7 or 8 holes rather than only 7 holes. Each player is given ten credits of reward when they started. Seven credit 
rewards will be added to the player's account for every round, he or she wins.

While playing,a playerr who does not have enough marbles will see their holes burnt. However, the burnt holes can be redeemed using the credits in the player's account in which one redemption of a burnt hole is equivalent to three credits.

Snake and Ladder. This game was designed to have three levels starting from beginner, intermediate and advanced levels to assist users in learning at different difficulty levels. The size of the game board for each level is different, i.e. 6 × 5 squares for beginner level, $10 \times 10$ squares for intermediate level and $12 \times 10$ squares for advanced level. The difficulty level increases as the size of the board game increases. A spinner is used in replacement of a dice. Some of the squares contain mystery boxes that will pop up questions which need to be solved by the players.

\section{Phase 3: Development}

Congkak was redeveloped using Java. Figure 2 shows the interface of the final version of Congkak. Once the player chose the holes to play (Figure $2 a$ ), he will take turns to play with the computer. The player drops one marble at every hole, including
Home, as he passes through the board in a clockwise direction (Figure 2b). The player who stops at an occupied hole will pick up all marbles in that hole and continues distributing the marbles. The player who stops at an empty hole on his opponent's side will end his turn; however, if he stops at an empty hole on his side, he can collect all marbles (if any) in the opposite hole and put into his Home.

The ultimate goal of this game is to collect as many marbles in the Home. The player with the largest collection of marbles is the winner, and 7 credits of rewards will be credited into his account. After a round play, player may not get enough marbles to fill in all holes on his side, and this hole will be burnt (Figure 2c). The reward in account can be used to redeem the burnt holes; 3 credits will be deducted from the player's account for every redemption made by the player (Figure $2 d$ ).

Snake and Ladder. This one or multi-player game was developed using Corona Lab. The three difficulty levels are made different from the size of the board game and difficulty of the popped-up questions. Figure 3 shows some of the interfaces of Snake and Ladder.

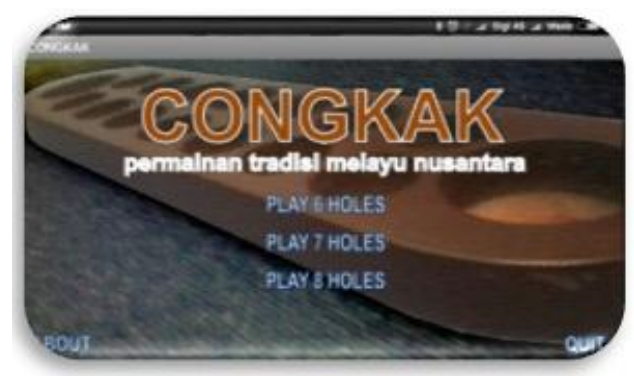

(a) Fexible board size

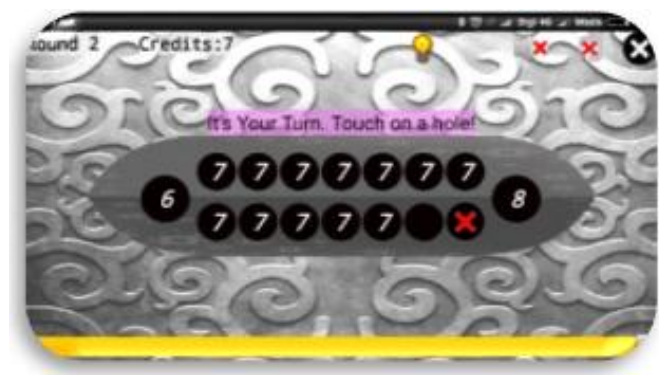

(c) The burnt hole remarked as $\mathrm{X}$

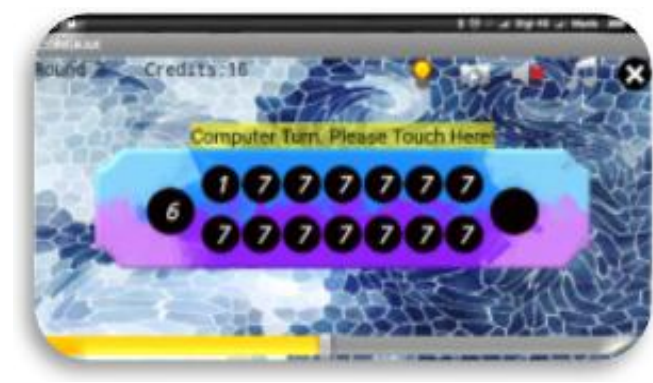

(b) Clockwise gameplay



(d) Redemption of rewards

Figure 2 Interface of Congkak 


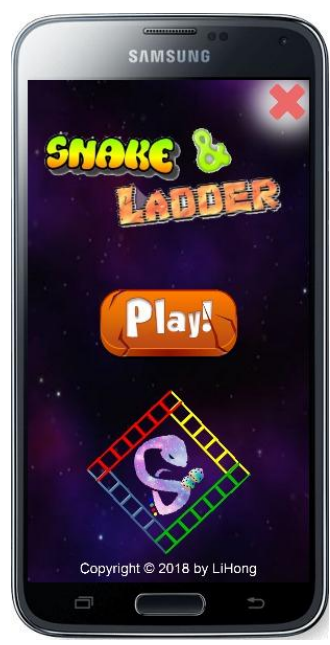

(a)

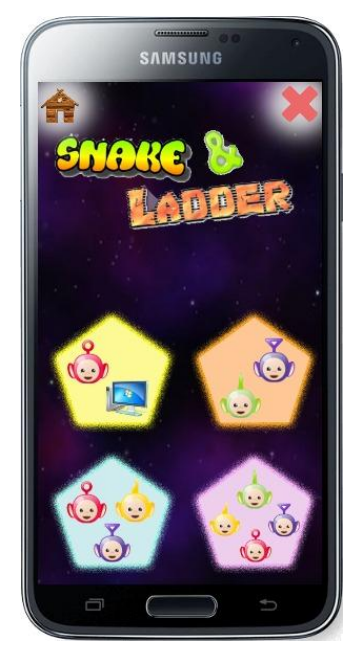

(b)



(c)

Figure 3 Interface of snake and ladder

A player can choose to play with computers, or with the maximum number of three other players (Figure $3 b)$. Figure $3 c$ shows the interface for the Intermediate level, which contains 100 squares. While playing, the player needs to solve simple Math problems popped up from the mystery boxes in order to continue playing. These questions vary in terms of their difficulties, according to the level of the game. Each of the correct answer is worth one credit, which can be accumulated and used to redeem the theme of the game board.

\section{Phase 4: Evaluation}

Figure 4 shows the procedure used in User Acceptance Test (UAT) which involved the demonstration of Congkak and Snake and Ladder, testing the apps and collection of data through questionnaires. Seventy respondents took part in the evaluation process in which 40 of them evaluated Congkak while 30 evaluated Snake and Ladder at two different events.

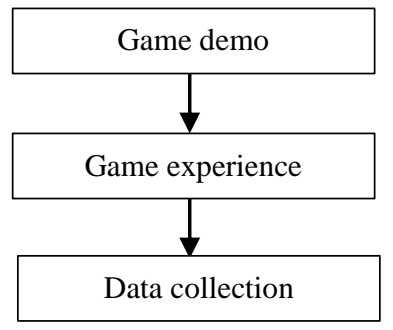

Figure 4 Evaluation procedures

Game demo. Prior to the game demo, both prototypes were installed on mobile devices. All the functions were explained and demonstrated to the respondents.

Game experience. Respondents play the game by taking turns with the computer; this allowed them to gain experience with the game.

Data collection. The systematic interview was conducted using self-construct questionnaires. The instrument for Congkak measures six constructs relating to perception towards reward in digital traditional games, i.e. the importance of rewards; level in which rewards are needed; motivation; survival and engagement. Snake and Ladder emphasize more on learning and therefore the constructs used were different from those used in the evaluation of Congkak. Both instruments follow the Likert scales as follows: 1=Strongly Disagree; 2=Disagree; 3=Neutral; 4=Agree and 5=Strongly Agree.

\section{Findings}

The main title is centered, and in times new roman 14-point, boldface type. Capitalize the first letter of nouns, pronouns, verbs, adjectives, and adverbs; do not capitalize articles, coordinate conjunctions, or prepositions. Leave one blank line after the title.

\subsection{Congkak}

The majority $(82.5 \%)$ of the respondents is in the age range of 21 to 29 years old. Others are between 14 to 20 years old $(12.5 \%)$ and 30 years old and above $(5 \%)$. Female participants are $55 \%$ more than the males, i.e. $77.5 \%$ of females compared to $22.5 \%$ of males. The majority (75\%) of them play games between 1 to 4 hours a day. Seven-point five percent of them only play less than 1 hour a day while $17.5 \%$ play more than 4 hours. This figure indicates that the 
majority of the respondents have experience in playing computer games, whether it is a traditional or contemporary game.

The mean score in Figure 5 shows a majority of the respondents have positive perceptions towards rewards; five out of six constructs scored above 4.0 which means the respondents are more towards strongly agree that rewards are important, needed at all difficulty levels, motivation, help players' survival as well as engage players to the game. The fact that rewards motivate players in Congkak is consistent with previous findings in [15, 20-21]. This provides insights into how rewards in digital traditional games can play a vital role in preserving culture. As claimed by $\mathrm{ChePa}$ and Yahya [22], sustainable engagement in digital traditional games can preserve country's cultural heritage.

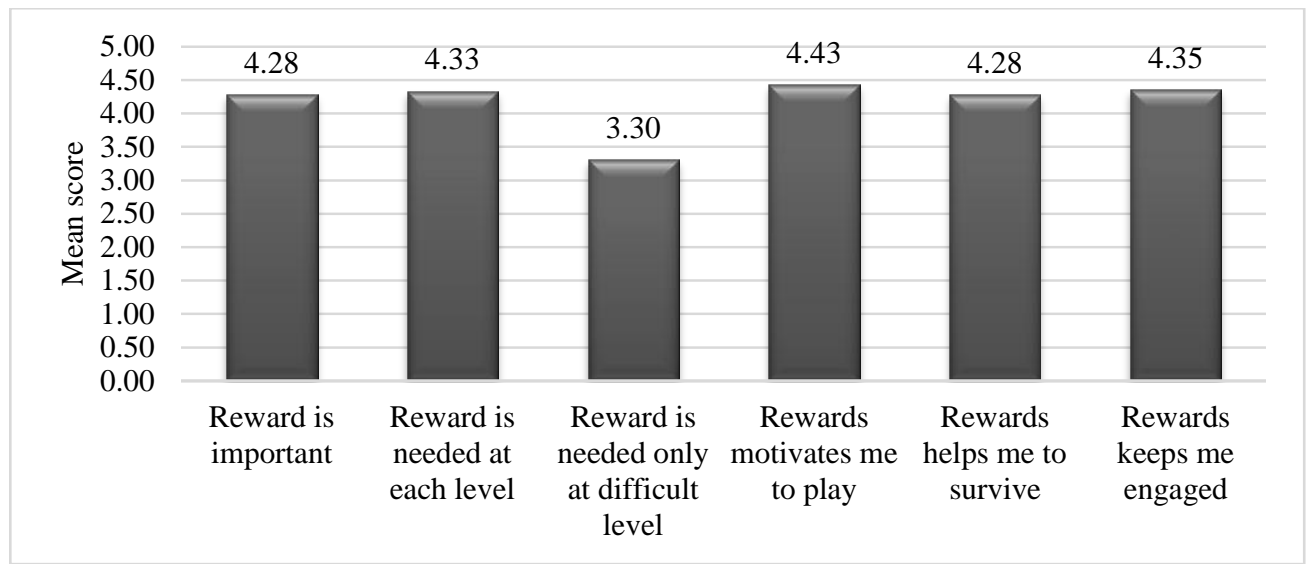

Figure 5 Respondents' perception towards rewards in Congkak

\subsection{Snake and ladder}

Respondents to this app include $3 \%$ of the 5 to 10 years old, $20 \%$ of the 11 to 15 years old, $20 \%$ of the 16 to 21 years old and $57 \%$ of the 21 years old and above. Female participants are $63 \%$ more than the males, i.e. 19 females as compared to 11 males. Ten percent never plays mobile games while the rest play either on daily, weekly, monthly or occasional basis with the distribution is almost the same, i.e. between 20 to $24 \%$. Out of this, only slightly half of them (57\%) have experience playing games that contain learning materials. The majority $(93 \%)$ of the respondents has heard about Snake and Ladder, and this is not surprising as it is the game everyone used to play during childhood. However, their familiarity is limited to the original version of Snake and Ladder which is played on paper or plastic board.

Five questions related to learning were asked during the systematic interview. Feedback from thirty respondents is as shown in Figure 6 below.



Figure 6 Respondents' perception on snake and ladder towards learning 
As indicated in the figure, Neutral and Agree responses dominated the feedback. Most of the respondents agree or strongly agree on the usefulness of the game, especially in sharpening their learning skills $(66.67 \%)$ and increasing their interest in learning $(56.67 \%)$. In total, there are 14 respondents who agree and strongly agree that the game makes it easier to do Mathematics. This number is slightly above the number of neutral responses (i.e. 12). The use of mystery box and questions helped to attract players as they know the rewards that will be granted when they are able to answer the questions correctly. As they solve the given problem for getting credits, they actually learn. To date, the evaluation of rewards was only conducted on Congkak. Similar evaluation on Snake and Ladder is yet to be conducted and reported. It has been mentioned earlier that Snake and Ladder focus more on learning and therefore the result of its evaluation cannot be compared with Congkak.

\section{Conclusion}

The work presented in this article was motivated by the awareness of the importance to preserve the nation's culture and values of these cultures to promote a country in the world. The Government of Malaysia, through the National Heritage Department and Ministry of Tourism, arts and culture have conducted various activities, events or sports on regular basis for the sake of promoting the country. This work serves as an additional effort to preserve traditional culture by applying computer or digital technology in line with the techno-savvy characteristics of the so-called millennials. While Congkak is meant for educating them about their own culture, game such as Snake and Ladder aimed to enhance their learning in Mathematics. Rewards were incorporated in both games for the purpose of making playing DTGs more exciting, interesting and engaging, hence can promote better perception and acceptance of DTGs. More studies are needed to investige what type of rewards are significant to which traditional game. Future development of digital traditional games should focus on adding only rewards which are significant.

\section{Acknowledgment}

This research is funded by Universiti Utara Malaysia (UUM) through University Grant (S/O Code: 13725 (2017)). Authors fully acknowledge UUM for the approved fund which makes this important research viable and effective. Credit also goes to research assistant Intan Nur Syafiqah Abdullah and game developers Tee Li Hong and Syamsul Bahrin Abdul Mutalib.
Conflicts of interest

The authors have no conflicts of interest to declare.

\section{References}

[1] Khalid S. Value of traditional games. Nurture. 2008(5):19-21.

[2] Zulkifli M, Putra A, Yusof M, Anuwar S, Norzaman NZ, Razali AF. Re-creation of Malaysian traditional game namely 'Baling Selipar': a critical review. International Journal of Science, Environment and Technology. 2014; 3(6):2084-9.

[3] https://www.superdataresearch.com/worldwidedigital-games-market/. Accessed 26 October 2018.

[4] https://www.ncbi.nlm.nih.gov/pmc/articles/PMC3244 307. Accessed 26 October 2018.

[5] ChePa N, Bakar NA, Mohd A. Usability evaluation of digital Malaysian traditional games. Jurnal Teknologi. 2015; 77(29):85-90.

[6] Prensky M. Digital game-based learning. Computers in Entertainment (CIE). 2003; 1(1).

[7] Kovačević T, Opić S. Contribution of traditional games to the quality of students' relations and frequency of students' socialization in primary education. Croation Journal of Education. 2014; 16(1):95-112.

[8] Felicia P. Digital games in schools: Handbook for teachers.2009.

[9] Jani J. Malaysian traditional games as innovation in teaching netball, modified from teaching games for understanding method in physical education. Proceedings of ISER international conference 2016 (pp.24-8).

[10] Samsudin MA, Haniza NH, Muhammad M and Abdul-Talib C. Utilizing Malaysian traditional games to implement kinesthetic intelligence approach in informal science learning environment. International Journal of Education and Research. 2014; 2(11): 13346.

[11] https://pages.uoregon.edu/moursund/Books/Games/Ga mes.pdf. Accessed 26 October 2018.

[12] Mohd Omar NF. A potential gasing as folk games product towards commercialized product in Malay craft (Doctoral dissertation, Universiti Teknologi MARA).2015.

[13] http://www.mostdangerousgamedesign.com/2013/08/t he-psychology-of-rewards-in-games.html. Accessed 26 October 2018.

[14] Abu Bakar NA, ChePa N, Hibadullah CF and Hussain A. Perception towards rewards in digital traditional games: experience from pilot study. International Journal of Engineering \& Technology. 2018; 7(3.20): 40-4.

[15] Richter G, Raban DR, Rafaeli S. Studying gamification: the effect of rewards and incentives on motivation. In gamification in education and business 2015 (pp. 21-46). Springer, Cham.

[16] Deterding S. Situated motivational affordances of game elements: a conceptual model. In gamification: using game design elements in non-gaming contexts, a workshop at CHI 2011. 
[17] Rapp A. The value of rewards: exploring world of warcraft for gamification design. In proceedings of the annual symposium on computer-human interaction in play companion extended abstracts 2016 (pp. 253-9). ACM.

[18] Siu K, Riedl MO. Reward systems in human computation games. In proceedings of the annual symposium on computer-human interaction in play 2016 (pp. 266-75). ACM.

[19] Phillips C, Johnson D, Wyeth P. Videogame reward types. In proceedings of the first international conference on gameful design, research, and applications 2013 (pp. 103-6). ACM.

[20] https://www.edutopia.org/blog/effective-rewardsgame-based-learning-vicki-davis. Accessed 26 October 2018.

[21] http://onlyagame.typepad.com/only_a_game/2005/08/ designing_rewar.html. Accessed 26 October 2018.

[22] Chepa N, Yahaya WA. Reality and challenges of malaysian digital traditional games. Journal of Engineering Science and Technology, Special Issue on ISSC.; 2017:209-18.



Nur Azzah Abu Bakar has been awarded with a Bachelor of Information Technology from Universiti Utara Malaysia in 1994 and M.Sc Information Technology (Science and System Management) from Universiti Kebangsaan Malaysia in 1998. Her research interest includes the Knowledge-Based System, especially in the aspect of Acquisition and Maintenance; Data Mining and Game Digitization. Her current position is a Senior Lecturer at the School of Computing, Universiti Utara Malaysia. Since 1998, she has taught various IT-related subjects at undergraduate and postgraduate level, and involved in supervision at both levels.

Email: nurazzah@uum.edu.my

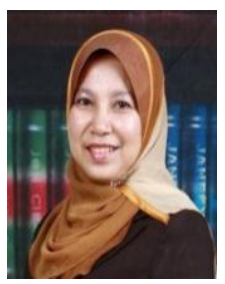

Noraziah ChePa has been awarded with a BSc in Computer Science and M.Sc in Computer Science from University Science Malaysia in 1999 \& 2000respectivelyy. Her research activities include Neuro Modelling, Game Based Modelling, and Agent Simulation. Her current position is a Senior Lecturer at the School of Computing, Universiti Utara Malaysia since she joined in May 2000. Having experiences in teaching more than twenty IT-related subjects for both under-graduate \& post-graduate levels and M.Sc supervisions. Having a deep interest with Neuro modelling in health-related issues, she is currently working on doctoral thesis on game-based modelling.

Email: aziah@uum.edu.my 